\title{
Calidad de la educación, justicia y libertad
}

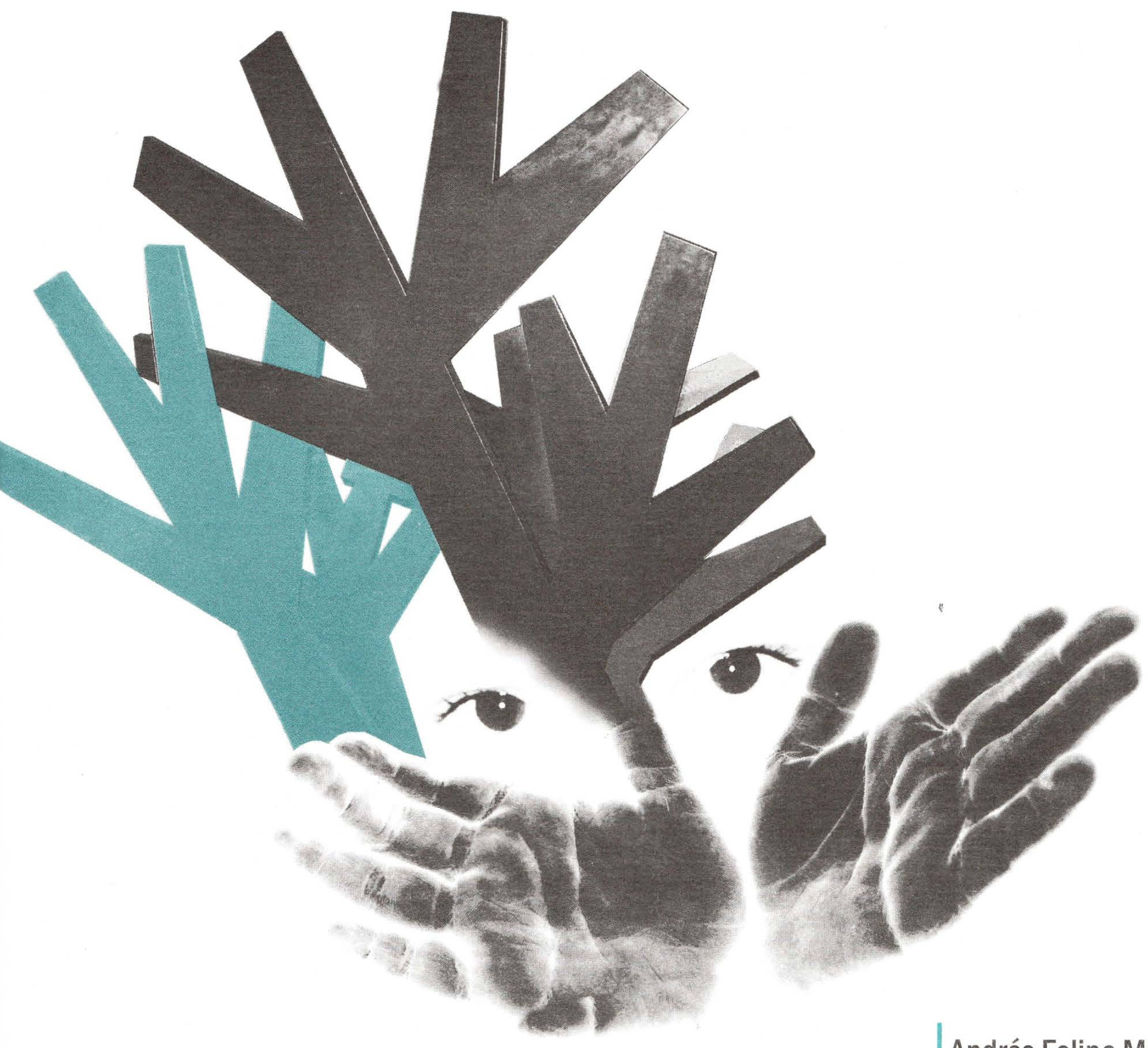

Andrés Felipe Mora Cortés 


\section{Andrés Felipe Mora Cortés es Politólogo de la Universidad Nacional de Colombia, Candidato a} Magíster en Ciencias Económicas en esa misma Universidad. Docente del Departamento de Ciencia Política de la Universidad Nacional de Colombia. Correo electrónico: andresfmora@gmail.com.

\section{Resumen}

Este ensayo explora la relación de doble vía existente entre calidad en la educación y política social. Después de definir una postura crítica frente a la teoría del capital humano como eje articulador de la relación calidad educativa-política social, el documento propone dos dimensiones desde las cuales la educación puede determinar los fundamentos políticos y normativos de una política social justa y creadora de libertad: i) por una parte, se enuncia la necesidad de un modelo educativo formador de sujetos morales dispuestos para la justicia; por otra ii) se considera la urgencia de formación de sujetos que valoren la política social desde la perspectiva de la libertad y no desde las necesidades de articulación a la ética del trabajo o la estética del consumo. Si la política social configura las condiciones socio-económicas para una educación de calidad, la calidad educativa edifica las bases políticas y normativas de una política social justa y creadora de libertad.

Palabras clave: política sociai, calidad en la educación, justicia, libertad.

\section{Abstract}

This paper explores the dual relationship between quality of education and social policy. With a critical position about the human capital theory as an articulating axis of the relation between quality of education and social policy, the author proposes two dimensions in which education can determine the political and statutory foundations of a fair freedomcreative social policy: i) the need for an educational model is stated for the formation of moral individuals prepared for justice; ii) the urgency is acknowledged for the formation of individuals that value social policy with a focus on freedom rather than based on the necessity of articulating to the ethics of work or esthetics of consumption. Whilst social policy shapes the socioeconomic conditions for the quality of education, quality of education, in sum, builds the political and statutory bases of a fair freedom-creative social policy.

Key words: Social policy, Quality of education, Justice, Freedom. 


\section{Presentación $n^{1}$}

La política social provee las condiciones socioeconómicas para una educación de calidad. La educación de calidad ofrece las bases políticas y normativas para una política social justa e integral. La relación es de doble vía. La ciudad de Bogotá ha avanzado notablemente en la creación y el fortalecimiento de las condiciones socioeconómicas para la prestación de un servicio educativo público y de calidad que materialice el derecho a la educación. No obstante, desde la escuela y desde los valores políticos que allí se imparten y se construyen, se definen los fundamentos políticos y normativos de una política social justa y solidaria que brinde las bases esenciales para el ejercicio de la libertad. Se sostendrá que el protagonismo asumido por la escuela en este sentido se asocia con la formación de calidad i) de sujetos dispuestos a construir las condiciones de moralidad para una política social justa y ii) de sujetos que comprendan la política social como espacio para la creación de libertad y no como un instrumento para la reproducción de la ética del trabajo o la profundización de la estética del consumo.
El documento se divide en cinco partes. En la primera de ellas se menciona el avance que la comprensión de la política educativa desde la perspectiva más amplia de política social ha representado para la creación y consolidación de un entorno socioeconómico garante de la educación de calidad en Bogotá. Seguidamente, sostiene que la relación política social-calidad en la educación es recíproca, pero se insistirá en los límites normativos y prácticos presentes en la teoría del capital humano como elemento articulador de dicha relación de reciprocidad. En contraste con dicha teoría y después de reivindicar la dimensión política de la política social, la tercera y cuarta parte del documento ofrece dos aspectos sobre los cuales la educación de calidad configura las bases normativas de una política social justa y creadora de libertad: por una parte, se señala la obligación de la escuela en términos de la formación de sujetos dispuestos a construir las bases morales de una política social justa; en "segundo lugar, se indica el deber de formar sujetos que valoren la política social como un campo para la creación de libertad y no como un medio para la articulación a la ética del trabajo o a la estética del consumo.

1 Este documento es producto del trabajo realizado en el marco de la investigación La educación y lo público: tendencias y construcciones participativas en Bogotá, financiado por el Instituto para la Investigación Educativa y el Desarrollo Pedagógico IDEP y adelantado por el Grupo Interdisciplinario de Estudios Políticos y Sociales del Departamento de Ciencia Política de la Universidad Nacional de Colombia y por la Corporación ConCiencia Política. 


\section{Las condiciones socio-económicas para una educación de calidad}

La propuesta política llevada a cabo por las administraciones recientes de la ciudad de Bogotá en materia de reforzamiento y creación de las condiciones socio-económicas para el ejercicio pleno del derecho a la educación, puede ser definida sistemáticamente dentro del concepto de nueva vulnerabilidad social. Dicho concepto se vincula con procesos de desigualdad social que encuentran su origen en la pobreza, la exclusión y la marginación. Miguel Vite $^{2}$ ofrece el siguiente esquema:

La pobreza hace referencia a los procesos que llevan a una baja o precaria integración económica. El desempleo o las condiciones precarias de empleo constituyen la causa fundamental de esta problemática. Sus efectos principales de la pobreza se asocian a la poca capacidad de reproducción del entorno familiar (alimentación, vestido, vivienda, etc.).

- La exclusión es concebida como un proceso que lleva a una baja o precaria integración institucional. La discriminación por género, edad, etnicidad y discapacidad puede ser determinante en este contexto. Desde esta dimensión de la desigualdad, las consecuencias se relacionan con la poca capacidad de reproducción e inserción a las instituciones sociales (educación, salud, derechos laborales, etc.)

2 Vite, Miguel. "La nueva vulnerabilidad social”, en: Revista Economía, Gestión y Desarrollo. Cali: Pontificia Universidad Javeriana, Facultad de Ciencias Económicas y Administrativas, No. 5. Noviembre de 2007. 
- La marginación se comprende como el proceso que lleva a una baja o precaria integración al sistema de servicios públicos. La baja integración social y regional constituyen la causa fundamental de este fenómeno, y los efectos se relacionan con falta de infraestructura, vivienda y saneamiento básico.

- Todas estas dimensiones de la desigualdad pueden hacerse presentes definiendo grados menores o mayores de vulnerabilidad social. Así, las dimensiones de la vulnerabilidad social presentadas ofrecen un esquema que puede servir de base para comprender la esencia del enfoque de derechos en el marco de las políticas sociales y su interés por promover las posibilidades de movilidad e integración social a través del ejercicio de la plena ciudadanía.

Bajo esta visión integral, las políticas tendientes a garantizar las condiciones socio-económicas para una educación de calidad han buscado brindar solución a las insuficiencias de oferta y demanda que impiden la materialización del servicio público educativo como derecho pleno en la ciudad de Bogotá.

Esta propuesta puede ser ilustrada rápidamente si se observan los resultados ofrecidos por las autoridades de la ciudad en los últimos años y la clara sintonía que estos alcances han tenido con el mejoramiento de la calidad educativa. El programa de Subsidios Condicionados a la Asistencia Escolar constituye un buen ejemplo de esta sinergia. De acuerdo con la Alcaldía Mayor de Bogotá:
Una estrategia sin precedentes en el país son los Subsidios Condicionados a la Asistencia Escolar, la cual benefició estudiantes de educación secundaria para estimular su retorno al sistema educativo y así evitar que abandonen el colegio antes de terminar el grado $11^{\circ}$. Los más de 44 mil estudiantes beneficiados se comprometen a asistir todos los días a clases para recibir el subsidio (\$60.000 cada dos meses) (...) La evaluación de impacto de los beneficios señala como efectos más significativos de la transferencia monetaria los siguientes: 1. El 99.99\% de los beneficiarios afirmó que el subsidio ha permitido aumentar su rendimiento académico, a prestar más atención en clases y llegar a tiempo al colegio porque tienen recursos para transportarse; 2. El $88 \%$ considera que el beneficio es la mayor motivación para seguir estudiando; 3. Cerca del $80 \%$ afirmó que utilizaron el dinero del subsidio para uniformes o materiales para el colegio; 4. El 78\% de los estudiantes dedican la mayor parte de su tiempo extraescolar a estudiar; 5. Un 20\% de los beneficiarios aumentaron la calidad de la alimentación; 6. Un 10.6\% de los beneficiarios con estos recursos contribuye a sufragar los gastos de su casa ${ }^{3}$

3 Alcaldía Mayor de Bogotá. Informe final Plan de Desarrollo "Bogotá sin indiferencia" 2004-2007. Bogotá: Alcaldía Mayor, 2007. Pg. 22.

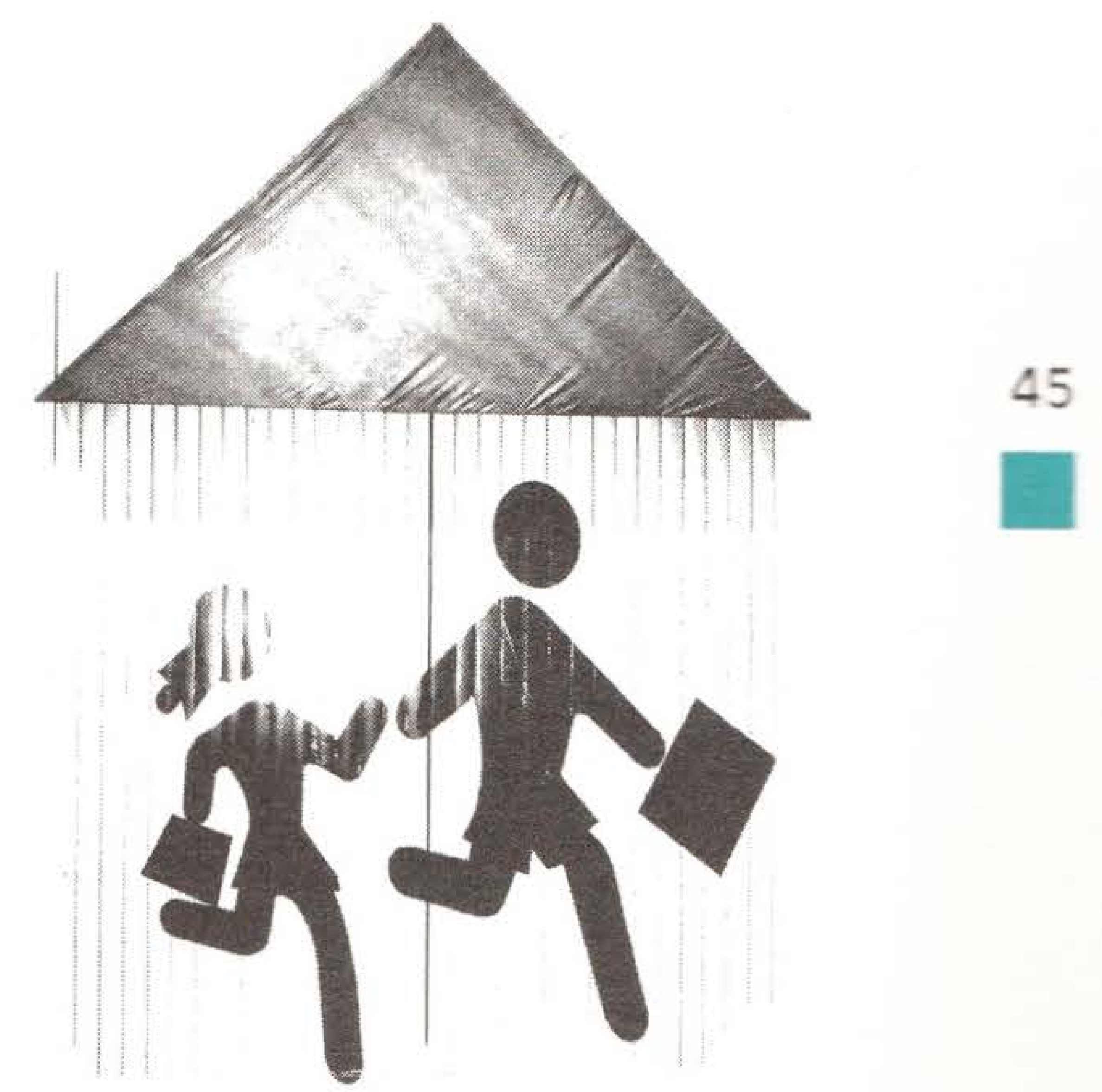


Es claro entonces, que la comprensión de la política educativa desde la perspectiva más amplia de la política social garantiza la consecución de resultados en materia de disponibilidad, acceso y permanencia que redundan en el mejoramiento de la calidad educativa. Sin embargo, esta relación no es unidireccional: si la política social ofrece las bases socio-económicas para una educación con calidad, la educación de calidad ofrece los fundamentos políticos y normativos para una política social justa y garante de la libertad. Después de haber señalado brevemente la relación política social-calidad en la educación, lo que queda del ensayo intentará demostrar cómo es posible establecer una relación calidad educativa-política social que, además de trascender el vínculo hegemónico que se ha establecido en términos de la teoría del capital humano, ofrezca claves para la formación de sujetos dispuestos para la libertad y la construcción colectiva de instituciones justas.

\section{Los límites del capital humano: la necesidad de politizar de la política social}

La cuestión sobre los factores que neutralizan las bondades sociales del modelo de desarrollo inspirado en el Consenso de Washington ha inquietado permanentemente a la ortodoxia y ha impulsado un mayor interés por comprender elementos más allá de lo económico para comprender el proceso del desarrollo. Que se contemplen factores no económicos como favorables para el crecimiento y la igualdad, no quiere decir, sin embargo, que dichos factores dejen de ser interpretados en clave económica, pues es preponderante que cualquier extensión realizada a las prescripciones neoliberales originales sea coherente con la esencia misma de las reformas a favor del mercado y con sus posibilidades de reproducción. Tal es el caso de la educación, que al inscribirse en el marco más amplio de la inversión en recursos humanos, ha sido comprendida en términos del capital humano necesario para aumentar el crecimiento, enfrentar la pobreza y cualificar la mano de obra.

Desde esta teoría, la inversión en recursos humanos constituye la mejor alternativa para encontrar un punto de equilibrio entre la búsqueda de mayores niveles de productividad y la minimización de la pobreza. El mayor crecimiento económico producido por el aumento en capital humano provocará, en el largo plazo, una mejor distribución del ingreso y de los beneficios del desarrollo. Así mismo, un mayor grado de escolaridad y niveles apropiados de salud, nutrición y adiestramiento de la mano de obra permitirán un sólido incremento en los niveles de productividad y crecimiento, así como un mejoramiento de las condiciones sociales de los países. 
Behrman (1993) testifica la relación virtuosa establecida entre crecimiento económico e inversión en recursos humanos: las mayores tasas de escolaridad se relacionan profundamente con un alto rendimiento social, con reducciones en la fecundidad y mortalidad, con niveles inferiores de analfabetismo, con mejoras de bienestar y salud y con la consolidación de la masa trabajadora cualificada requerida para el mejor desempeño económico. Así mismo, altos grados de salud y nutrición favorecen la esperanza de vida, disminuyen las presiones demográficas y, en el largo plazo, minimizan las presiones fiscales generadas por los gastos en salud curativa. Por último, los programas de adiestramiento de la mano de obra aumentan la rentabilidad y productividad del sector privado.

Igualmente, J.L. Londoño (1996) presenta un trabajo paradigmático en este terreno, pues asegura que es la educación el factor aislado más importante que contribuye a la persistencia de la desigualdad y al aumento de la pobreza en un entorno caracterizado por las buenas prácticas de la estabilidad macroeconómica, la eficiencia microeconómica y la internacionalización de la economía. Desde esta óptica, la inversión en capital humano aparece como la alternativa más eficiente y socialmente rentable para erradicar la pobreza, aumentar la productividad y generar crecimiento económico.

Sólo un acelerado aumento de la formación de capital humano puede apartar rápidamente a la región de la pobreza. De hecho, lo que la región necesita podría llamarse un shock de capital humano: educación básica universal para todos los jóvenes durante los próximos 20 años para que el promedio de instrucción de la fuerza de trabajo llegue a nueve años por persona. Un alto crecimiento sin este tipo de formación de capital humano reducirá el número de pobres con el correr del tiempo, pero un mayor nivel de educación lo logrará con mucha mayor celeridad. Además, (...) la rápida expansión de la educación de por síllevará a una tasa de crecimiento más alta (2).

Si empíricamente la teoría del capital humano rechaza las causas estructurales de la pobreza por considerarlas cortoplacistas e irrelevantes cuando se comparan con las ventajas del adiestramiento de la mano de obra, es porque teóricamente considera que el origen de la pobreza es individual y microeconómico: los agentes son pobres porque debido a la ausencia de capital humano, su aporte productivo es bajo y, por lo tanto, el nivel salarial que se correspondería con dicha productividad en un mercado laboral desregulado sería igualmente bajo. Se espera, entonces, que el capital humano haga más productivos a los individuos y que, por esta vía, aspiren a salarios más elevados en el marco de mercados laborales flexibles.

Bajo estos parámetros, Londoño insiste en que durante la segunda posguerra (1950-1995) la expansión de la educación fue lenta y discriminatoria de los sectores más pobres de la población. Continúa con un ejercicio de simulación que intenta proyectar los impactos que un shock de capital humano"(universalización de la educación primaria) generaría sobre los niveles de pobreza de la región. Su pronóstico parte de 1995 y se extiende hasta 2015, y supone la existencia de seis escenarios probables en materia de crecimiento económico, desigualdad y acumulación de capital humano. En su primer corte (2005) estos fueron son los resultados de su ejercicio: 


\section{Cuadro No. 1}

\begin{tabular}{|c|c|c|c|}
\hline \multicolumn{4}{|c|}{ Resultados Simulación - Londoño (1996) } \\
\hline $\begin{array}{l}\text { Con un crecimiento } \\
\text { económico (promedio } \\
\text { 1995-2005) }\end{array}$ & $\begin{array}{l}\text { Una desigualdad } \\
\text { (promedio 1995- } \\
\text { 2005) }\end{array}$ & $\begin{array}{l}\text { Y un promedio de } \\
\text { capital humano (tasas } \\
\text { de escolaridad para } \\
2005 \text { ) }\end{array}$ & $\begin{array}{l}\text { El número de pobres en Amé- } \\
\text { rica Latina para el año } 2005 \\
\text { se ubicaría }\end{array}$ \\
\hline \multirow{2}{*}{ Lento $(1.9 \%)$} & Gini 0.56 & \multirow{2}{*}{7.0 años } & Entre 170 y 180 millones \\
\hline & Gini 0.50 & & Entre 140 y 150 millones \\
\hline \multirow{2}{*}{ Moderado (2.24\%) } & Gini 0.56 & \multirow{2}{*}{7.5 años } & Entre 150 y 160 millones \\
\hline & Gini 0.50 & & Entre 130 y 140 millones \\
\hline \multirow{2}{*}{ Rápido (3,0\%) } & Gini 0.56 & \multirow{2}{*}{8.1 años } & Entre 140 y 150 millones \\
\hline & Gini 0.50 & & Entre 100 y 110 millones \\
\hline \multicolumn{4}{|c|}{ Hechos Observados } \\
\hline $\begin{array}{l}\text { Crecimiento promedio } \\
\text { 1995-2005 en América } \\
\text { Latina: } 2.6 \%\end{array}$ & $\begin{array}{l}\text { Gini en América } \\
\text { Latina Promedio } \\
\text { 1995-2005: } 0.53\end{array}$ & $\begin{array}{l}\text { Tasa de escolaridad } \\
\text { promedio en América } \\
\text { Latina 2005: } 8.7 \text { años }\end{array}$ & $\begin{array}{l}\text { Número de pobres en América } \\
\text { Latina en 2005: } 214 \text { millones. }\end{array}$ \\
\hline \multicolumn{4}{|c|}{$\begin{array}{l}\text { Diferencia Escenario Simulado (crecimiento rápido, Gini del } 0.56 \text { y escolaridad de } 8.1 \text { años) y } \underline{\text { Hechos }} \\
\text { Observados: } 70 \text { millones de pobres aproximadamente. }\end{array}$} \\
\hline
\end{tabular}

Fuente: CEPAL Anuario Estadístico 2006.

Como se observa, el escenario recreado por los hechos empíricos en América Latina es aquel que se caracteriza por un crecimiento rápido, un coeficiente de Gini entre 0.56 y 0.50 y una tasa promedio de escolaridad superior a 8.1 años. Sin embargo, el nivel de pobreza no se corresponde por lo proyectado en la simulación, y la realidad demuestra que ésta se ve superada en su pronóstico por 70 millones de pobres aproximadamente. En contra de las cifras planteadas por la simulación de Londoño, los hechos empíricos demuestran, entonces, la ineficacia de la teoría de capital humano para erradicar la pobreza. La educación, vista desde esta óptica, ofrece muy poco a la política social.
A la ineficacia del capital humano como medio para reducir la pobreza, se une también la crítica ética que se le puede realizar. En este sentido, Amartya Sen se interesa por analizar el alcance y validez del concepto de desarrollo basado en el capital humano. Debido a que la concepción de capital humano comprende a los individuos como instrumentos para alcanzar una mayor productividad y un mayor crecimiento económico, Sen propende por un concepto de desarrollo asociado a la libertad y al entendimiento de la libertad del individuo como fin en sí mismo. La concepción de capital humano, que pasa por la dotación y perfeccionamiento de habilidades, la educación y el aprendizaje en favor de 
la consolidación de economías más productivas, debe ser trascendido por una concepción que considere el desarrollo como la ampliación de las capacidad de la población para realizar actividades elegidas (libremente) y valoradas (Sen, 1999: 13). La meta del desarrollo económico debe ser la libertad, no el crecimiento económico; el crecimiento económico constituye un instrumento que amplía la capacidad individual para asumir la libertad. En este contexto, la comprensión de la educación es fundamentalmente diferente. Sen (1998) sostiene que:

Si la educación hace que la persona sea más eficiente en la producción de bienes, es claro que hay un mejoramiento del capital humano. Este mejoramiento puede agregar valor a la producción de la economía y aumentar el ingreso de la persona que ha sido educada. Pero aún con el mismo nivel de ingreso, esa persona puede beneficiarse de la educación por la posibilidad de leer, argumentar, comunicar, elegir con mayor información, ser tenida en cuenta más seriamente por otros y así sucesivamente. De modo que los beneficios de la educación son mayores que su función de capital humano en la producción de bienes. La perspectiva más amplia de capacidad humana puede abarcar -y valorar- estas funciones adicionales (...) Hay, sin embargo, una diferencia crucial entre las dos perspectivas, que se relaciona en cierta medida con la distinción entre medios y fines. El reconocimiento del papel de las cualidades humanas en la promoción y el sostenimiento del crecimiento económico - por importante que sea- no nos dice nada acerca de por qué lo primero que se busca es el crecimiento económico. Si, en cambio, se da énfasis a la expansión de la libertad humana para vivir el tipo de vida que la gente juzga valedera, el papel del crecimiento económico en la expansión de esas oportunidades debe ser integrado a una comprensión más profunda del proceso de desarrollo, como la expansión de la capacidad humana para llevar una vida más libre y más digna ${ }^{4}$
En resumen, la teoría del capital humano, como fundamento de la política educativa, ofrece muy poco a la política social: resulta ineficaz en términos de la reducción de la pobreza, y es desdeñable desde el punto de vista ético debido a su intención de convertir a los individuos en instrumentos para el crecimiento económico. Se requiere, entonces, encontrar nuevas dimensiones de reciprocidad entre la educación y la política social. La calidad educativa no debe evaluarse desde la perspectiva de la promoción de competencias para el trabajo productivo. La escuela debe erigirse como un escenario fundamental para politizar la política social y trascender la perspectiva economicista y productivista que la reduce a "empresa" promotora del capital humano ¿Por qué? Fundamentalmente, porque la instauración de un modelo de política social solidario y que garantice el ejercicio pleno de los derechos económicos y sociales depende del grado y modelo de politización de la sociedad en cuestión. El carácter de la invención política de la cuestión social, la profundidad de la cultura política democrática y la conciencia con respecto al deber de exigir la materialización y respeto por los derechos económicos y sociales como constituyentes de la ciudadanía, y no como contrapartidas caritativas $\mathrm{o}$ asistencialistas, instituyen, en su conjunto, los pilares fundamentales para catalizar el tránsito hacia un modelo de política social no mercantilizado ni residual.

4 Sen, Amartya. "Capital humano y capacidad humana", en: Cuadernos de Economía. Bogotá: Universidad Nacional de Colombia, Facultad de Ciencias Económicas, Vol. XVII, No. 29. Diciembre de 1998. Pg. 25-36. 
Para el caso colombiano, por ejemplo,

la trayectoria histórica de la protección social ilustra la idea de que, habida cuenta de que no se habría podido tener un sistema de protección social sin politización, el déficit de politización contribuye a la esclerosis del sistema antiguo (de 1945 a 1993), mientras que el tipo de politización que preside la aparición del nuevo (desde 1994) determina su alcance y sus limitaciones ${ }^{5}$

En efecto, la falta de comprensión de la política social como un proyecto político que debe fundamentarse en principios democráticos respetuosos del consenso, ha favorecido la creación elitista y "desde arriba" de modelos de política social destinados simplemente a la gestión de las crisis de legitimidad del sistema y favorecedores de modelos focalizados y residuales cargados de clientelismo e ineficacia. La intención normativa de la Constitución Política de 1991 no se ha correspondido con el soporte político que sustenta sus posibilidades de materialización: la ausencia de modelos populistas, la configuración de un modelo delegativo de democracia, el autismo tecnocrático, la estigmatización provocada por ciertas medidas de política social y la inercia histórica que ideológicamente vincula la política social con la caridad, el infortunio individual, el parasitismo y el asistencialismo, han truncado el camino hacia la reivindicación legítima y democrática de los derechos económicos y sociales.

La relación ciudadanía-política social es recíproca y mutuamente estructurante: simultáneamente, resulta imprescindible reconocer la política económica y social como la base fundamental para el ejercicio pleno de la ciudadanía, pero garantizando también, la participación política en los espacios institucionales definidos en las fases de formulación implementación y evaluación de las políticas de desarrollo. Ambos elementos permitirán trascender los límites impuestos por la teoría de la lucha contra la pobreza y promover, en su lugar, la construcción participativa de mecanismos solidarios de materialización de los derechos económicos, sociales y culturales. Este modelo de política social y ciudadanía enfatiza el principio de igualdad en las oportunidades de vida como derechobase del ciudadano, legitimado no sólo en términos de una más amplia justicia social, sino también como prerequisito para el buen funcionamiento de la sociedad. Además asume como indispensable el fortalecimiento de una cultura política defensora de la política social no como una caridad o un "favor que se hace, ni siquiera como un derecho que es legítimo exigir, sino como un elemento que define y constituye a la ciudadanía. En definitiva, la configuración integral y solidaria de la política social es posible solamente si se encuentra en el centro del proyecto político de la sociedad; es decir, si es verdaderamente politizada.

Por lo tanto, la educación de calidad, si quiere convertirse en la fuente de politización y justificación normativa de una política social justa, integral y efectiva debe propender por la formación i) de sujetos dispuestos a construir las condiciones de moralidad para una política social justa y ii) de sujetos que comprendan la política social como espacio para la creación de libertad y no como un instrumento para la reproducción de la ética del trabajo o la estética del consumo.

5 Le Bonniec, Yves. "Colombia: una apuesta aún incierta”, en: Oscar Rodríguez (Comp). Sistemas de protección social: entre la volatilidad económica y la vulnerabilidad social. Bogotá: Centro de Investigaciones para el Desarrollo, Universidad Nacional de Colombia, 2005. Pg. 159. 


\section{La educación y las fuentes morales de la justicia social}

La justicia concierne a la distribución de las cargas y beneficios sociales en materia de poder, derechos, oportunidades, recursos y privilegios, y a la manera como puede ser defendida dicha distribución: de ahí su contenido moral. Sin embargo, son varias las fuentes de moralidad propuestas en las teorías de la justicia. Desde David Hume y Adam Smith, por ejemplo, es posible encontrar una línea de defensa de la moralidad vinculada al concepto de simpatía imparcial con los intereses de todos los afectados. Hume insistía en las condiciones de egoísmo moderado e igualdad para garantizar el apego incondicional de las personas a las reglas de la justicia. Adam Smith defendía el principio no egoísta de la simpatía y consideraba que la reprobación moral de las acciones, preferencias y decisiones de los demás podría realizarse solo en un contexto de interacción en que fuera posible realizar un cambio inter-subjetivo con la situación del otro. Más recientemente, este criterio de moralidad se ha relacionado con la valoración realizada por un observador imparcial que ofrece un criterio común para la ponderación de los valores e intereses de los individuos.
Otras posturas han considerado que los principios de moralidad son aquellos principios que un agente racional elegiría detrás de un velo de la ignorancia adecuadamente concebido. En esta línea, se ha planteado que la moralidad puede ser instaurada desde una situación en que los agentes estén provistos por un velo de la ignorancia que impida el conocimiento de sus identidades, pero que les permita el conocimiento pleno de su entorno, en una situación de igual probabilidad de ser cualquiera de las personas presentes en dicha situación. Si se supone que los agentes racionales deciden en esta situación de igual probabilidad de ganar o perder, optarán por un principio que maximice el beneficio promedio de todas las personas involucradas. En este contexto, John Rawls considera que,

podemos garantizar una elección imparcial de principios preguntando que elegiría la gente si se le negara la clase de conocimiento que les permitiera manipular los principios en su propio favor. Los principios justos son aquellos que surgen de una situación de elección equitativa: por lo tanto el slogan es: justicia como equidad ${ }^{6}$ 
La representación de una posición original, en la cual los agentes se ubican detrás de un velo de la ignorancia, permite a J. Rawls definir tres principios de justicia relacionados con: 1) derechos civiles y políticos iguales, 2) competencia abierta a posiciones ocupacionales ventajosas y de decisión y 3) el principio de diferencia: las desigualdades deben disponerse de manera que mejoren la posición del peor situado.

Este último principio de diferencia es uno de los elementos que más se le ha criticado a Rawls, pero es el más importante en materia de política social. Vale la pena, por tanto, seguir con detenimiento el argumento rawlsiano que defiende este principio en términos del tránsito de la libertad natural a la igualdad liberal, y de ésta a la igualdad democrática. En este camino Rawls reconoce la igualdad como la única base justa de la distribución para, posteriormente, partir desde una distribución equitativa hasta una distribución orientada por el principio de diferencia. Esta es la línea argumentativa.

Desde los trabajos de Adam Smith -pasando Friedrich von Hayek- se ha considerado que cualquier resultado distributivo es justo si se llega a él por el intercambio en un mercado libre. Se considera que en el marco del mercado existe una igualdad formal de oportunidades en que todos tienen el mismo derecho legal de acceder a los recursos y a todas las posiciones sociales ventajosas. Este es el sistema de la libertad natural. No obstante, para Rawls este sistema de pensamiento resulta desdeñable debido a que ignora que la distribución inicial de los bienes está fuertemente influida por contingencias arbitrarias naturales y sociales que determinan los resultados de dichas relaciones de intercambio. Para Rawls las capacidades y talentos naturales, las circunstancias sociales y los accidentes asociados al infortunio o la buena suerte impiden la entrada abarcativa por parte de los individuos en el sistema de libertad natural.
El criterio de igualdad liberal, por su parte, agrega al principio de libertad natural la condición adicional de equidad de oportunidades. Las expectativas de aquellos con las mismas capacidades, aspiraciones y talentos no deben verse afectadas por su posición o clase social. Se debe garantizar una "carrera abierta a los talentos"; se debe eliminar toda fuente de desigualdad exceptuando la dotación genética. Esta postura es también injusta según Rawls:

aún cuando [el concepto liberal] funcione a la perfección al eliminar la influencia de las contingencias sociales, todavía permite que la distribución de la riqueza y el ingreso sea determinada por la distribución natural de las capacidades y de los talentos... y este resultado es arbitrario desde una perspectiva moral ${ }^{7}$

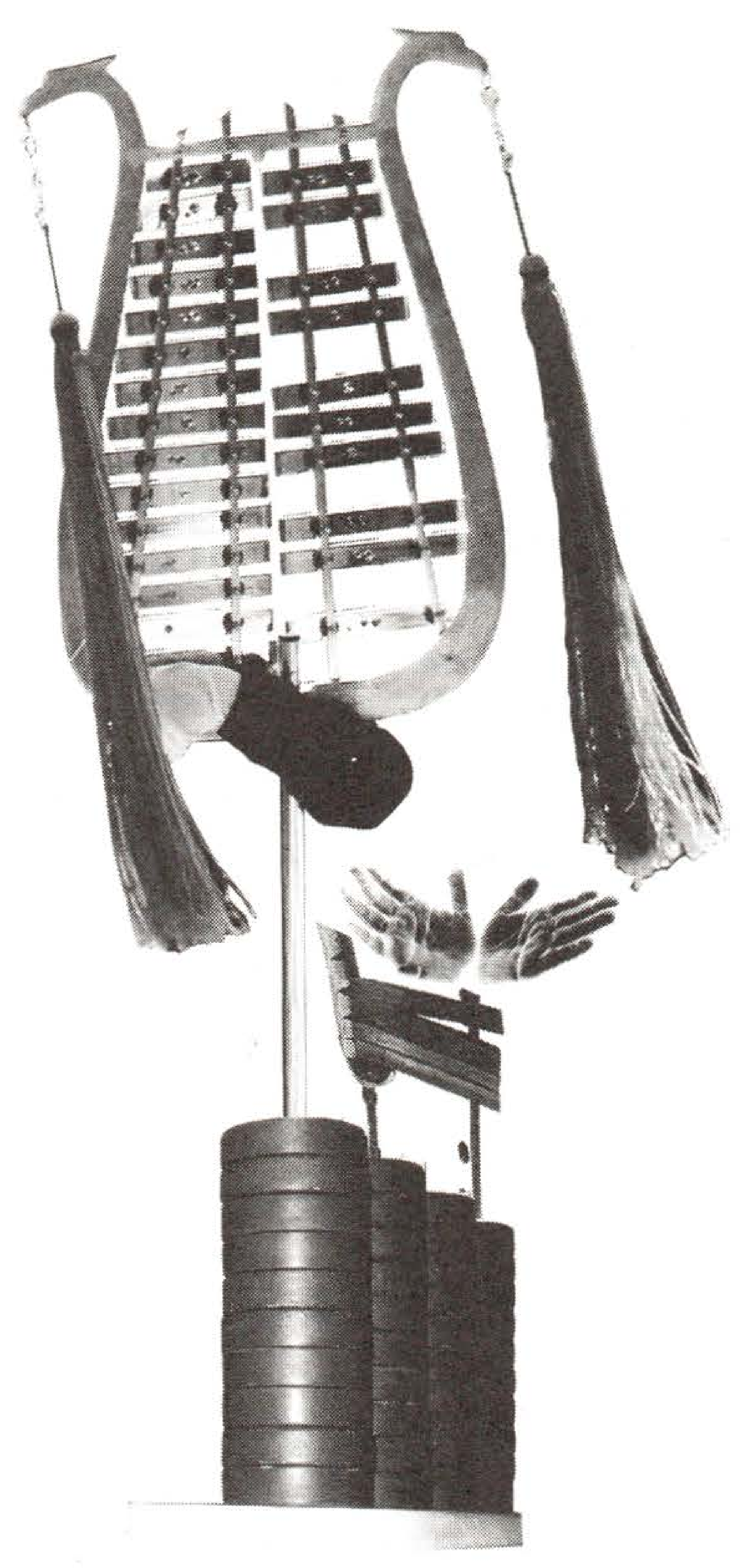


J. Rawls insiste, entonces, en la necesidad de avanzar hacia una igualdad democrática que no determine la participación de los hombres en los beneficios y cargas de la cooperación social de acuerdo con su fortuna social o su suerte en la lotería natural. Por lo tanto, inicialmente para Rawls, todas las diferencias en logros se basan en principios moralmente arbitrarios, y la igualdad de resultados constituye la base fundamental de una sociedad justa. En este sentido, la cuestión radica en definir cómo pasar de la igualdad estricta de resultados (o ingresos) al principio de diferencia defendido por el mismo Rawls ${ }^{8}$ ¿Es posible encontrar un camino diferente al definido por la representación contrafáctica del velo de la ignorancia para construir una sociedad justa? Sí lo es. Este principio de imparcialidad y moralidad surge cuando se indaga sobre los argumentos que podrían no ser razonablemente rechazados en una situación de igualdad argumentativa. Los individuos deben preguntarse si hay cosas que nadie razonablemente aceptaría en ausencia de coerción, incluyendo la coerción implícita de un resultado de desacuerdo.

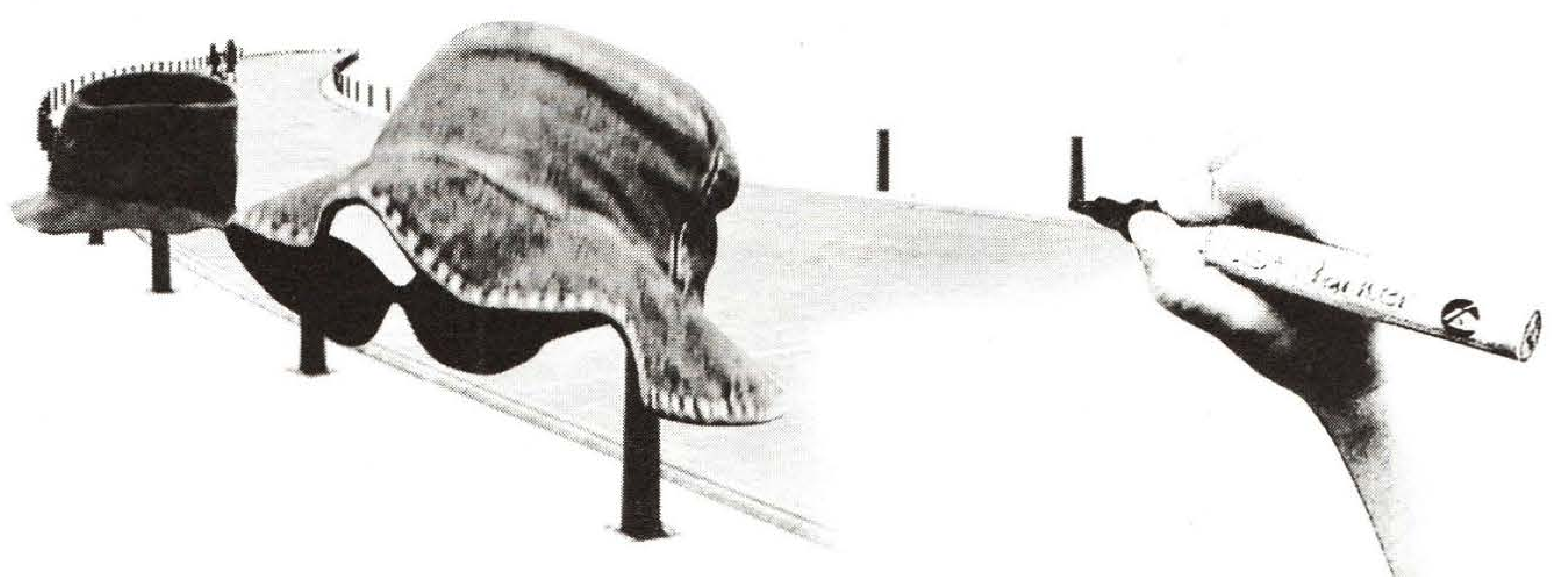

En el marco de las teorías de la justicia, esta es la pregunta fundamental que concierne a la política social ¿Puede ser considerado el principio de diferencia como una regla social susceptible de no ser rechazada razonablemente por individuos libres en una situación igualdad? Sí lo es. Pare ello basta señalar las alternativas argumentativas que llevan a Rawls a seguir el camino desde la igualdad plena al principio de diferencia como elemento fundamental de una sociedad justa. Muy sucintamente Barry (1997) afirma que:

Las desigualdades que surgen de los principios de justicia rawlsianos pueden estar justificadas para aquellos a quienes les va peor en su aplicación (...) Lo esencial ęs el principio de diferencia (...) Podemos expresar esta circunstancia de forma más aproximada diciendo que la gente más desfavorecida de dicha sociedad estará entonces tan acomodada como sea posible (...) a los más desfavorecidos (sea cual sea su identidad) no se les podría favorecer más: cualquier cambio institucional tendría el efecto de convertir a los más desfavorecidos (sea cual sea su identidad) en más desfavorecidos ${ }^{9}$

7 Rawls J. en Barry B, 1995. Op. Cit. Pg. 63

8 El principio de diferencia de Rawls sostiene que "Todos los valores sociales -la libertad y la oportunidad, el ingreso y la riqueza y las bases del autorrespeto- han de ser distribuidos igualmente a menos que una distribución desigual de cualquiera, o de todos estos valores, sea ventajoso para todos (...) la injusticia, entonces, son desigualdades que no son para beneficio de todos" (Barry, 1995: 246).

9 Barry, Brian. La justicia como imparcialidad. Barcelona: Paidós, 1997. Pg. 105. 
La política social justa parte, entonces, de la existencia de sujetos morales preparados para ofrecer argumentos que razonablemente no serían rechazados por los demás en una situación de igualdad. En este punto el papel de la educación resulta fundamental. La formación de sujetos dispuestos para la justicia consiste en la formación de sujetos democráticos y defensores de los procedimientos de toma colectiva de decisiones en igualdad de condiciones. Procedimentalmente, los sujetos deberían estar preparados para no rechazar ninguna concepción del bien, pues se considera que ñinguna concepción del bien tampoco tiene la posibilidad de no ser rechazada razonablemente. En el marco del proceso de valoración y reconocimiento de las diversas concepciones del bien los sujetos deben ser portadores de los principios de "escepticismo moderado" (ninguna concepción del bien se puede sostener de forma justificable con un grado de certeza que garantice su imposición a quienes la rechazan), "igual respeto" (convencimiento propio de que nadie podría rechazar razonablemente nuestra explicación), y "restricción epistemológica" (es razonable rechazar cualquier pretensión política o fundamento de política pública basada directamente en una concepción particular del bien).
La igualdad democrática y la defensa del principio de diferencia como fundamentos de una política social justa, dependen de la formación de sujetos dotados de una dimensión moral que les permita asumir un compromiso con la búsqueda de argumentos que podrían no ser objetables por ningún individuo en una situación de igualdad. La educación se posiciona como un lugar estratégico para la refundación de la subjetividad individual en los términos que una política social justa requiere. La subjetividad es política; es una dimensión propia e inherente a la multiplicidad de sujetos, poderes y saberes constituyentes del mundo social. La escuela debe abordar la cuestión de la subjetividad desde el ámbito de la acción política, es decir, desde el modo de obrar de personas defensoras de un discurso público y de acciones políticas alternativas que redunden en la edificación de un modelo justo de política social. No obstante, la función de la educación no se limita a esta dimensión normativa; de la educación depende, igualmente, la construcción de subjetividades que comprendan el campo de la política social desde las posibilidades de creación de libertad, y no desde visiones estrechas que la reduzcan a un instrumento para la articulación a los imperativos de la ética del trabajo o la estética del consumo. 


\section{Superando la ética del trabajo, evadiendo la estética del consumo}

La pregunta por la pobreza es una pregunta sobre cómo se producen socialmente los pobres y sobre qué significa ser pobre. De la respuesta que se ofrezca a estas cuestiones depende la definición de los objetivos e instrumentos que en el marco de la política social son seleccionados para combatir dicho flagelo. El concepto de pobreza puede ser rastreado con precisión desde los orígenes del capitalismo hasta nuestros días; sin embargo, esta posibilidad de seguimiento histórico no implica que el concepto haya sido el mismo y que tampoco haya sufrido cambios en el contexto de las transformaciones más amplias observadas en la sociedad. En este sentido, Zygmunt Bauman ${ }^{10}$ propone dos dimensiones de comprensión de la pobreza, asociadas ambas con el desarrollo del capitalismo, pero diversas en materia de su significado y mecanismos de producción social: a la pobreza relacionada con una sociedad de la producción, sustentada en la ética del trabajo y comprendida desde la problemática del desempleo, contrapone un significado emergente de pobreza surgida en una sociedad consumista, inspirada en una estética del consumo y definida en términos de la expulsión de los agentes del sistema del mercado. El análisis del tránsito de una comprensión de la pobreza a otra devela la estrechez de las políticas sociales inspiradas en uno u otro concepto de la pobreza y revela, igualmente, el objetivo de contención y control social que caracteriza a ambas definiciones.

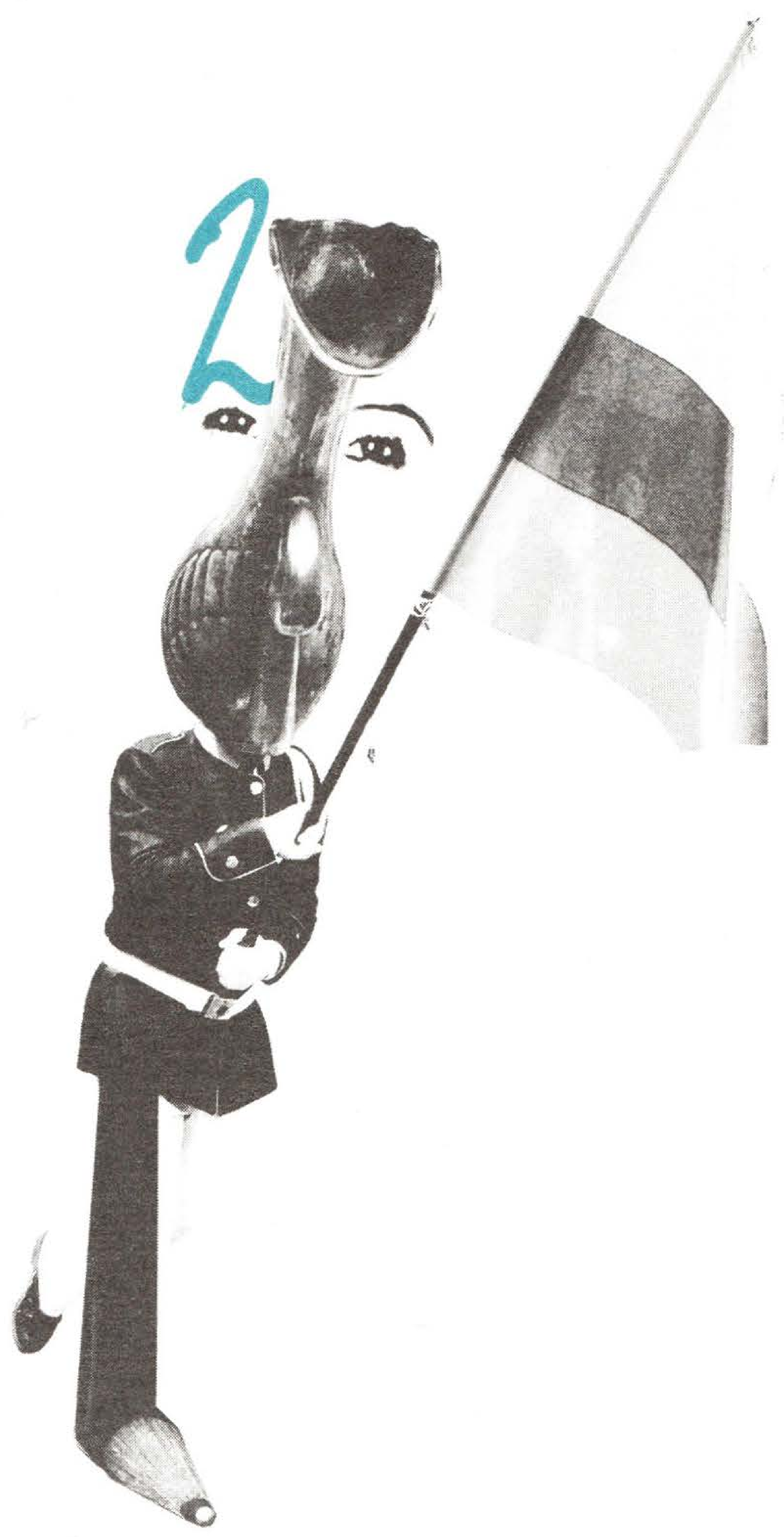


En los orígenes del capitalismo, la ética del trabajo fue definida como una norma de vida. El acto de trabajar fue concebido como un valor en sí mismo que ennoblecía y jerarquizaba a los individuos. El trabajo fue considerado como la base del progreso y cada acción individual que se le opusiera era caracterizada como inmoral, bárbara o antisocial. El trabajo constituyó, entonces, un mecanismo de disciplinamiento y control social que catalizó el proceso de modernización y la conversión de los individuos en engranajes integrados al mecanismo complejo del desarrollo capitąlista: "la cruzada por la ética del trabajo era la batalla por imponer el control y la subordinación. Se trataba de una lucha por el poder en todo, salvo en el nombre; una batalla para obligar a los trabajadores a aceptar, en homenaje a la ética y la nobleza del trabajo, una vida que ni era noble ni se ajustaba a sus propios principios de moral" (Bauman, 2003: 21).

Se consideró que el trabajo educaba, civilizaba. La tradición, la costumbre y el ocio pronto fueron despreciados y la venta de la fuerza de trabajo se convirtió en la única forma decente y moralmente aceptable de ganarse el derecho a la vida. La estrategia consistió en hacer tan difícil y paupérrima la vida de los pobres que se garantizara su aceptación o la búsqueda de un trabajo igualmente miserable. La política social, vista desde esta óptica, debería ser lo suficientemente degradante y despreciable como para inducir a los pobres a trabajar. Esta fue la filosofía de la "Ley de Pobres" implementada en Inglaterra entre 1820 y 1830.

Este es el primer vínculo entre política social, trabajo y control: la política social debía edificarse de una manera miserable para inducir a los individuos al trabajo y promover y reproducir mecanismos de control social traducidos en la subordinación, la rutina, la disciplina y la supervisión. La ética del trabajo fue antagónica de la libertad: "La gente sin empleo era gente sin patrón, gente fuera de control: nadie los vigilaba, supervisaba ni sometía a una rutina regular, reforzada por oportunas sanciones" (Bauman, 2003: 35).

Posteriormente, esta lectura del trabajo se modificó y éste dejó de ser visto como un fin para convertirse en un medio: en el contexto del espíritu de la empresa y de la movilidad social ascendente, el trabajo se concibió como un medio para la libertad, la riqueza y la protección social. El principio contributivo, el premio al esfuerzo y los salarios diferenciados sirvieron como medios para la promoción y diferenciación social. Si en un primer momento la política social se vinculaba al trabajo porque su penuria obligaba al establecimiento de relaciones salariales, en el siglo XX la política social se articulaba al trabajo porque éste último constituía su fundamento: los derechos sociales, económicos y culturales que podrían servir de inspiración para la política social, dependían, para su materialización, del trabajo y del pleno empleo. El principio contributivo sirvió de mecanismo de control, y junto con la defensa de las posibilidades de movilidad social ascendente, se perdió de vista la dimensión de la política social que exige la transformación en las estructuras sociales. El derecho al trabajo se erigió como el sustento de la integración y el orden social en el marco del capitalismo del bienestar. El carácter precario de una política social que en el siglo XIX debía inducir al trabajo, fue desplazado, en el siglo $\mathrm{XX}$, por la definición contributiva de una política social que no funcionaba sin contraprestación. 
No obstante, la motivación de movilidad social no fue la única que promovió el acceso de los individuos a los mercados laborales; el consumo en masa fue comprendido también como el sentido de la producción en masa, y surgió la base para la sociedad de los consumidores.

Pronto la ética del trabajo sería sustituida por la estética del consumo; pronto la pobreza se disociaría del desempleo y se comprendería desde la desconexión de los individuos respecto al mecanismo del mercado. Es esta la concepción de pobreza que prevalece en el mundo contemporáneo: en el mundo del consumo el deseo se aparta de la espera, el entusiasmo depende de la novedad y la visita diaria al mercado constituye la fuente de identidad, éxito y reconocimiento. Además, las identidades deben tener el don de la flexibilidad, deben ser temporarias: "Las identidades, como los bienes de consumo, deben pertenecer a alguien; pero sólo para ser consumidas y desaparecer nuevamente (...) Siendo este el requisito, no tiene sentido buscarlas en otra parte que no sea el mercado" (Bauman, 2003: 51). Siguiendo a Bauman, la nueva dimensión temporal, la separación entre el deseo y la espera y la ausencia de libertad que este nuevo entorno social presupone pueden ser definidas de la siguiente manera:

Cuando el deseo es apartado de la espera, y la espera se separa del deseo, la capacidad de consumo puede extenderse mucho más allá de los límites impuestos por las necesidades naturales o adquiridas, o por la duración misma de los objetos del deseo (...) Para los consumidores maduros y expertos, actuar de ese modo es una compulsión, una obligación impuesta; sin embargo, esa "obligación" internalizada, esa imposibilidad de vivir su propia vida de cualquier otra forma posible, se les presenta como un libre ejercicio de voluntad ${ }^{11}$
La estética del consumo que se superpone -aunque no desplaza- a la ética del trabajo se caracteriza por la ausencia de rutinas, por la configuración de un estado de elección permanente y por la creación constante de deseos cambiantes y nunca satisfechos. El trabajo se subsume a la estética del consumo: los trabajos deben ser intensos, placenteros, estar inmersos en una dimensión estética para no ser considerados inútiles o degradantes. El desempleo es llevadero si hay posibilidades de consumo, de no "aburrimiento". Los modelos tradicionales de política social basados en el trabajo no constituyen remedios ni para el "aburrimiento" ni para la imposibilidad de ejercer individualmente una estética del consumo reconocida y valorada socialmente. Se requieren dinero, ingresos, centros comerciales, gimnasios, parques; es decir, medios y entornos para el consumo.

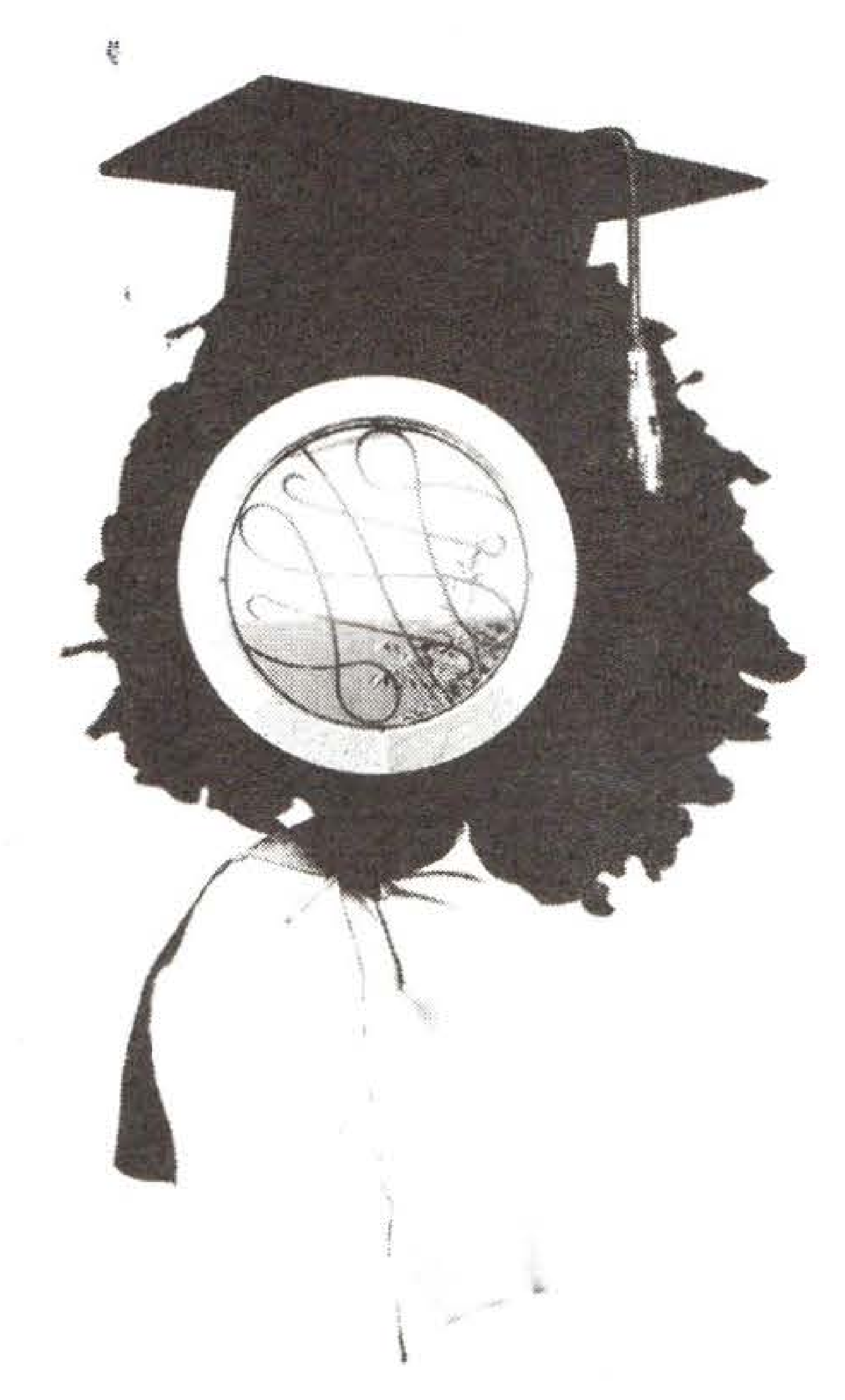


En esta línea, la libre elección que supuestamente caracteriza a la estética del consumo sirve para definir la pobreza como un problema individual; la expulsión de los circuitos mercantiles es debida a la falta de capacidades personales para aprovechar las oportunidades y leer adecuadamente las señales que emite el mercado. La ética del trabajo, aunque subsumida a la estética del consumo, continúa sirviendo de justificación para condenar y señalar a los marginados, a pesar de la insuficiencia de empleo. Los individuos eligen la miseria al no aprovechar las oportunidades brindadas por la sociedad. Toda desviación de la ética del trabajo y de la estética del consumo constituye una patología individualmente elegida que debe ser castigada o ignorada para que quienes adoptan caminos "antisociales" sufran las consecuencias de manera inclemente. Todo ello porque la sociedad brinda la "libertad de elegir", por lo cual se considera moralmente defendible y justificable.

En este contexto, la política social es comprendida desde los objetivos e instrumentos que articulan los sujetos a los circuitos mercantiles. Y en consonancia con la creencia en el origen individual de la pobreza, dicha política se define en términos de modelos residuales y compensatorios que -mediante la mercantilización de los derechos sociales y la instauración de normas de mercado en cada ámbito de la justicia social- buscan recrear modelos de control funcionales a la exclusión y la desigualdad. Más aún, el tono despectivo y peyorativo que acompaña al señalamiento de los pobres hace que la frontera entre la política social asistencialista y residual y la criminalización de la pobreza sea totalmente tenue.
Este recorrido histórico sobre la categoría de la pobreza permite concluir que resulta indispensable escindir la política social de la ética del trabajo y de la estética del consumo. Es urgente definir una política social inspirada en una ética para la vida; es decir, una política social que tome como máxima el derecho a la existencia independientemente del principio contributivo y de la mediación con el mercado laboral defendida por la ética del trabajo. Igualmente, es imprescindible remover toda justificación mercantil para la formulación e implementación de la política social: su politización y defensa desde las demandas por el ejercicio pleno de los derechos sociales, económicos y culturales constituyen la base fundamental para trascender la visión mercantil que la estética del consumo impone sobre la política social. La escuela debe formar sujetos que consideren el campo de la política social como un terreno para la libertad y el ejercicio de los derechos. El cambio en esta mentalidad implica un desafío enorme para la calidad educativa; y es aquí donde se construye la dimensión política de una política social alejada del control y la subordinación que implica el trabajo y de la mercantilización y el carácter residual que le otorga el consumo. 


\section{Conclusión}

La educación no es impotente frente a la pobreza; esto resulta evidente aún cuando se trasciende una perspectiva que vincule ambos aspectos en términos únicamente del nivel de ingresos de los individuos y de la rentabilidad que la educación genera en este contexto. La educación cumple un papel fundamental en el proceso de politización y justificación normativa de la política social, es decir, de la política llamada a maximizar el nivel de bienestar social mediante la redistribución del ingreso, la riqueza y las oportunidades para salir de la pobreza, la marginación y la exclusión. La escuela está llamada a formar sujetos dispuestos a encontrar la base de la moralidad institucional en procedimientos democráticos que aseguren el consenso en dinámicas argumentativas susceptibles de no ser razonablemente rechazadas. Y a construir mentalidades individuales que disocien la política social de la ética del trabajo y la estética del consumo que en general le han servido de inspiración, pero también de fuente de reduccionismos e intenciones de control y pérdida de libertad. Para finalizar es importante aventurar una máxima que ilumine el modelo de política social aquí defendido y que puede ser construido únicamente con el soporte de la escuela; para ello vale la pena remitirse a Sófocles quien en Antígona sentenció: Soy libre, exento de injusticia. 


\section{Bibliografía}

Alcaldía Mayor de Bogotá. Informe final Plan de Desarrollo "Bogotá sin indiferencia" 2004-2007. Bogotá, D. C.: Alcaldía Mayor, 2007.

Barry, Brian. La justicia como imparcialidad. Barcelona: Paidós, 1997.

Barry, Brian. Teorías de la justicia. Barcelona: Gedisa Editorial, 1995.

Bauman, Zygmunt. Trabajo, consumismo y nuevos pobres. Barcelona: Gedisa Editorial, 2003.

Behrman, Jere. "Inversión en recursos humanos", en: Informe Anual 1993. Washington: Banco Interamericano de Desarrollo, 1993.

Le Bonniec, Yves. "Colombia: una apuesta aún incierta”, en: Oscar Rodríguez (Comp). Sistemas de protección social: entre la volatilidad económica y la vulnerabilidad social. Bogotá: Centro de Investigaciones para el Desarrollo, Universidad Nacional de Colombia, 2005.

Londoño, Juan Luis. Pobreza, desigualdad y formación del capital humano en América Latina, 1950-2025. Washington:Estudios del Banco Mundial sobre América Latina y el Caribe, 1996.

Sen, Amartya. "Teorías del desarrollo a principios del siglo XXI", en: Biblioteca Digital de la Iniciativa Interamericana de Capital Social, Ética y Desarrollo - www.iadb.org/etica, 1999.

Sen, Amartya. "Capital humano y capacidad humana", en: Cuadernos de Economía. Bogotá: Universidad Nacional de Colombia, Facultad de Ciencias Económicas, Vol. XVII, No.29. Diciembre de 1998.

Vite, Miguel. "La nueva vulnerabilidad social", en: Revista Economía, Gestión y Desarrollo. Cali: Pontificia Universidad Javeriana, Facultad de Ciencias Económicas y Administrativas, No.5. Noviembre de 2007. 